\title{
KLASTERING INDUSTRI DI KABUPATEN KUDUS MENGGUNAKAN METODE FUZZY C-MEANS
}

\author{
Pratomo Setiaji \\ Fakultas Teknik, Program Studi Sistem Informasi \\ Universitas Muria Kudus \\ Email: pratomo.setiaji@umk.ac.id \\ Wiwit Agus Triyanto \\ Fakultas Teknik, Program Studi Sistem Informasi \\ Universitas Muria Kudus \\ Email: wiwit.agus@umk.ac.id
}

\begin{abstract}
ABSTRAK
Penelitian ini menggunakan metode klastering Fuzzy C Means, yang digunakan untuk klastering industri di Kabupaten Kudus, teori ini merupakan penggunaan dari teori klastering Fuzzy C Means. Klastering industri di kabupaten Kudus dilaksanakan sebagai upaya membantu pemerintah, khususnya departemen perindustrian perdagangan dan koperasi Kabupaten Kudus dalam melakukan pembinaan industri kecil dan menengah. Klastering industri merupakan langkah awal dalam pembinaan industri kecil dan menengah, karena dengan klastering, keberadaan industri akan lebih terkelompok berdasarkan jumlah unit usaha, jumlah tenaga kerja, nilai investasi. Metode yang digunakan dalam penelitian ini adalah pengambangan metode Fuzzy C Means, metode Fuzzy C means merupakan salah satu metode klastering yang bisa mengolah data yang tidak pasti.Tujuan dari penelitian ini adalah menghasilkan suatu klastering yang bisa diterapkan untuk melakukan pengelompokan data industri di Kabupaten Kudus. Hasil dari penelitian ini adalah analisa dan perancangan Analisa Dan Perancangan Sistem Informasi Klastering Industri Di Kabupaten Kudus Menggunakan Metode Fuzzy C-Means, sehingga dari hasil penelitian ini dapat di gunakan Dinas Perindustrian perdagangan dan Koperasi pemerintah membina dunia Industri.
\end{abstract}

Kata kunci: fuzzy c means, industri, klastering.

\section{ABSTRACT}

This study using Fuzzy C Means clustering method, which is used for clustering of industry in Kudus, this theory is the use of the theory of Fuzzy C Means clustering. Industry clustering in Kudus district implemented as an effort to help the government, especially the ministry of trade and cooperative Holy District in fostering small and medium industries. Industrial clustering is the first step in the development of small and medium industries, due to clustering, where the industry will be grouped based on the number of business units, the amount of labor, the value of the investment. The method used in this study is floating Fuzzy C Means, Fuzzy C means clustering is one method that can process data pasti.Tujuan of this research is to produce a clustering that can be applied to industry grouping data in Kudus. The results of this research is the analysis and design Analysis and Design of Information Systems Industry clustering in Kudus regency Method Using Fuzzy C-Means, so the results of this study can be used Department of Industry, Trade and Cooperatives foster world governments Industry.

Keywords: fuzzy c means, industry, clustering.

\section{PENDAHULUAN}

Dalam Rencana Pengembangan Ekonomi Kreatif Indonesia 2009-2015, industri kreatif adalah bagian tak terpisahkan dari ekonomi kreatif. Industri kreatif berpotensi untuk dikembangkan terutama di Indonesia, karena bangsa Indonesia memiliki sumberdaya insani kreatif dan warisan budaya yang kaya. Industri kreatif bila terus digali potensinya dan dikembangkan berkelanjutan yang berfokus pada penciptaan barang dan jasa dengan mengandalkan keahlian, bakat dan kreativitas sebagai kekayaan intelektual, tidak dapat dipungkiri dapat memperkuat citra \& identitas bangsa Indonesia dan dapat memberikan kontribusi secara signifikan bagi perekonomian bangsa untuk bangkit, bersaing dan meraih keunggulan dalam ekonomi global. 
Data mining merupakan suatu metode yang terdapat banyak cara dalam pengolahan data yang dapat digunakan, salah satunya adalah dengan menggunakan metode K-Means Clustering yaitu sebuah algoritma untuk mengklasifikasikan atau mengelompokkan objek-objek. Data Industri Kecil Menengah (IKM) Sepatu di wilayah Jawa Tengah. Pengolahan data pada Dinas Perindustrian dan Perdagangan (DINPERINDAG) Povinsi Jawa Tengah khususnya dari IKM Sepatu masih dalam bentuk yang belum pengolahan dengan baik. Dengan teknik pegolahan data mining untuk mengklasifikasikan data IKM Sepatu se-Provinsi Jawa Tengah dapat membantu dalam mengelompokkan data yang selama ini dilakukan secara manual dan tidak objektif. [1].

Fuzzy C-Means merupakan (FCM) merupakan teknik pengklasteran dimana tiap-tiap data ditentukan oleh derajat keanggotaannya. Semakin besar nilai derajat keanggotaan data dalam suatu klaster maka semakin besar pula data tersebut menjadi anggota klaster tersebut. Hasil clustering kemudian diproses atau dievaluasi menggunakan nilai $F$-measure dimana sebelumnya harus diketahui nilai precission dan nilai recall terlebih dahulu. Pengujian dilakukan pada dua jenis sebaran data yaitu sebaran data yang sama dan sebaran data yang berbeda dengan jumlah dataset yaitu 30 dataset, 90 dataset dan 120 dataset. Dari beberapa pengujian yang dilakukan menunjukkan bahwa nilai F-measure tertinggi cenderung berada pada klaster 3 [2].

Fuzzy C-Means adalah suatu teknik pengklasteran data yang mana keberadaan tiap-tiap data dalam suatu klaster ditentukan oleh nilai keanggotaan. Konsep dasar FCM, pertama kali adalah menentukan pusat klaster yang akan menandai lokasi rata-rata untuk tiap klaster. Pada kondisi awal, pusat klaster ini masih belum akurat. Tiap-tiap data memiliki derajat keanggotaan untuk tiap-tiap klaster. Dengan cara memperbaiki pusat klaster dan nilai keanggotaan tiap-tiap data secara berulang, maka akan dapat dilihat bahwa pusat klaster akan bergerak menuju lokasi yang tepat. Perulangan ini didasarkan pada minimasi fungsi obyektif [3].

Dalam jurnal ini akan dipublikasikan hasil penelitian yang telah dilakukan mengenai klastering industri di Kabupaten Kudus menggunakan Metode Fuzzy C-Means. sebagai upaya membantu pemerintah daerah dalam rangka mempermudah dalam pembinaan industri kecil maupun menengah.

\section{METODOLOGI PENELITIAN}

Jenis Penelitian ini adalah penelitian terapan, penerapan itu diarahkan pada penggunaan secara praktis di bidang kehidupan sehari-hari. Penelitian ini diselenggarakan dalam rangka mengatasi masalah nyata dalam kehidupan,. Penelitian ini menguji manfaat dari teori-teori ilmiah serta mengetahui hubungan empiris dan analisis dalam bidang-bidang tertentu. Implikasi dari penelitian terapan dinyatakan dalam rumusan bersifat umum, bukan rekomendasi berupa tindakan langsung. Setelah sejumlah studi dipublikasikan dan dibicarakan dalam periode waktu tertentu, pengetahuan tersebut akan mempengaruhi cara berpikir dan persepsi para praktisi. Penelitian terapan lebih difokuskan pada pengetahuan teoretis dan praktis dalam bidang-bidang tertentu bukan pengetahuan yang bersifat universal dalam hal ini adalah bidang teknologi. Penelitian terapan mendorong penelitian lebih lanjut, menyarankan teori dan praktek baru serta pengembangan metodologi untuk kepentingan praktis. Penelitian terapan dapat pula diartikan sebagai studi sistematik dengan tujuan menghasilkan tindakan aplikatif yang dapat dipraktekan bagi pemecahan masalah tertentu

Pendekatan yang digunakan metode yang digunakan dalam klastering industri di Kabupaten Kudus menggunakan metode Fuzzy C-Means menggunakan metode Linear Sequential/Waterfall model. Model ini merupakan model klasik yang bersifat sistematis, berurutan dalam membangun software. Desain dikerjakan setelah kebutuhan selesai dikumpulkan secara lengkap. Desain dalam penelitian ini meliputi: pemodelan proses, desain database dan desain interface. Teknik sampling yang digunakan adalah Sampling Acak Sederhana (Simple Random Sampling) Random Sampling adalah metode paling dekat dengan definisi probability sampling. Pengambilan sampel dari populiasi secara acak berdasarkan frekuensi probabilitas semua anggota populasi. Instrumen yang digunakan dalam penelitian ini adalah penggunaan tool phpmyadmin sebagai graphic user interface dalam mengelola database sehingga dalam pembuatan view, table, triger, strore procedure bisa dilakukan dengan mudah. Metode pengumpulan data yang nantinya digunakan pada penelitian ini adalah menggunakan pemodelan berorientasi obyek (Object oriented design) dengan metode pengumpulan Sumber Data berupa data Primer data yang diperoleh langsung dari Dinas Perindustrian perdagangan dan Koperasi Kabupaten Kudus baik melalui pengamatan, pencatatan atau penelitian terhadap obyek penelitian, yaitu data unit industri yang ada di kabupaten kudus. Data Sekunder data yang diperoleh selain dari obyek penelitian baik dari dokumen-dokumen, buku-buku maupun informasi-informasi dari pihak lain, yaitu buku tentang perindustrian dan klastering. 
Desain model yang digunakan dalam membangun sistem ini adalah menggunakan perancangan Object Oriented Desain (OOD) dan tool yang digunakan adalah Unified Modelling Language (UML). OOD adalah metode yang membawa kita ke dekomposisi berorientasi objek. Dengan menerapkan desain berorientasi objek, kita dapat menciptakan perangkat lunak yang tangguh dengan meminimalisasi penulisan ekspresi serta mengurangi risiko yang melekat dalam pengembangan sistem perangkat lunak yang kompleks [4]. Desain model yang termasuk di dalam UML adalah Use Case diagram, class diagram, sequence diagram, activity diagram, state diagram, collaboration diagram.

Teknik pengumpulan dan analisis data dalam penelitian ini adalah menggunakan observasi, studi pustaka, dan interview. Observasi dilakukan ke lokasi desa di Kabupaten Kudus, interview dilakukan dengan sumber data yaitu pihak perangkat desa di Kabupaten Kudus serta sampel penelitian dan studi pustaka dilakukan dengan mencari literatur dan jurnal mengenai Sistem Informasi.

Teknik analisa data dilakukan dengan tiga tahapan, yaitu : (1) mengidentifikasi dan menganalisa masalah sistem yang berjalan (problem analysis), dalam hal ini dilakukan analisa mengenai kendalakendala dalam proses penerimaan dan pengelolaan dana desa yang sudah digunakan selama ini, (2) mengidentifikasi dan menganalisa kriteria dan performance sistem yang dibutuhkan (requirements analysis), dalam hal ini dilakukan analisa mengenai kriteria sistem dana desa yang dibutuhkan, (3) memberikan alternatif sistem yang diusulkan (generating systems alternative). Pada bagian ini dilakukan pemilihan sistem beserta input, proses dan output dari sistem informasi dana desa yang disesuaikan dengan kebutuhan.

\section{HASIL PENELITIAN DAN PEMBAHASAN}

Sesuai dengan metodologi penelitian yang telah diteetapkan, berikut adalah hasil penelitian yang telah dicapai.

\subsection{Analisa Sistem}

Dari hasil pengamatan observasi di lapangan, masalah yang dihadapi adalah masih sulitnya mengelompokan industri di kabupaten kudus sehingga dengan adanya pengelompokan akan mempermudah dalam pembinaan industri kecil maupun menengah, dari kendala-kendala yang berhasil di analisa, maka dapat diidentifikasi kebutuhan sistem informasi adalah suatu sistem yang dapat membantu mengelompokan industri di kabupaten kudus. Kebutuhan informasi bagi pemangku kebijakan dimana informasi pengelompokan industri tersebut bisa menjadi acuan bagi pemangku kebijakan untuk menentukan rencana selanjutnya agar industri bisa menjadi lebih maju dan berkembang.

\subsection{Solusi Alternatif Sistem}

Dari analisa kebutuhan informasi, dapat diberikan alternatif solusi sistem, sistem yang dibutuhkan adalah Klastering Industri di Kabupaten Kudus menggunakan Metode Fuzzy C-Means sistem yang ada dapat diakses oleh semua orang yang mempunyai kewenangan untuk hal tersebut sehingga ini akan dapat memenuhi kebutuhan dan dapat mengatasi semua kendala yang selama ini dirasakan. Untuk mendukung pelaksanaan Klastering Industri di Kabupaten Kudus menggunakan Metode Fuzzy C-Means ini, perlu adanya dukungan sistem komputer yang memadai, baik dari segi hardware maupun software. Dalam melakukan pemilihan hardware maupun software tersebut perlu mempertimbangkan beberapa hal diantaranya dalam pengadaan hardware maupun software harus memperhatikan kebutuhan sistem saat ini maupun yang akan datang.

Dalam pengembangan sistem informasi ini perlu adanya pertimbangan biaya yang minimum tetapi mendapatkan hasil yang optimal. Kebutuhan SDM dalam pengembangan Klastering Industri di Kabupaten Kudus menggunakan Metode Fuzzy C-Means ini juga sangat diperlukan, sebagai orang yang akan menjaga, menggunakan dan merawat sistem, kebutuhan SDM pada sistem ini adalah sebagai berikut: 


\subsection{Desain Sistem}

Hasil dari analisa yang telah dilakukan kemudian dituangkan ke dalam model sistem dalam bentuk diagram pengguna, rincian struktur penyimpanan data dan layout tampilan aplikasi yang akan dihasilkan.

\subsubsection{Diagram Use Case}

Use Case adalah spesifikasi dari kumpulan aksi yang dijalankan oleh sistem [5]. Diagram Use Case untuk Klastering Industri di Kabupaten Kudus Menggunakan Metode Fuzzy C-Means di tunjukkan pada gambar 1.

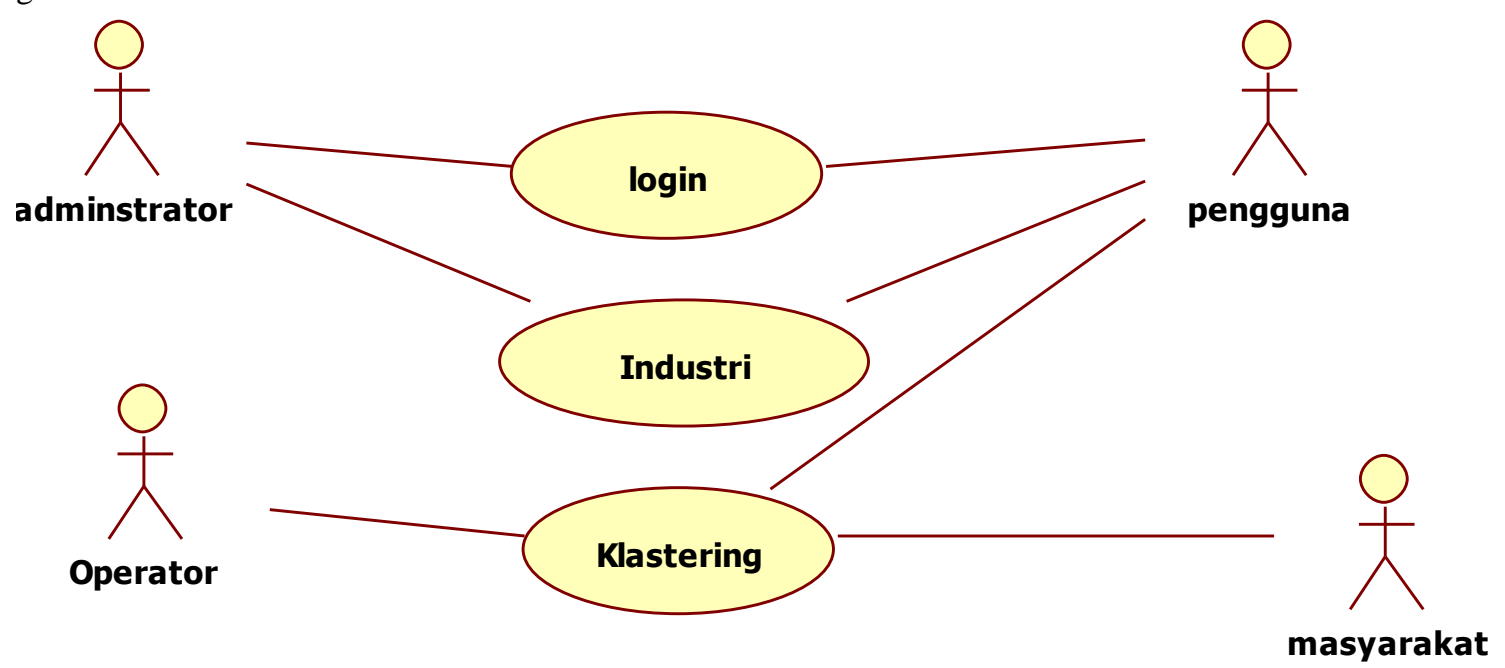

Gambar 1. Diagram Use Case

\subsubsection{Struktur Class Diagram}

Aplikasi database yang digunakan untuk mengembangkan aplikasi adalah database server $M y S Q L$ yang bersifat opensource. Terdapat sebuah database yang dirancang klastering industri di Kabupaten Kudus Menggunakan Metode Fuzzy C-Means yaitu dbklastering. Database tersebut di desain menggunakan class diagram yang strukturnya ditunjukkan pada gambar 2 .

\begin{tabular}{|c|c|c|}
\hline User & dtIndustri & klastering \\
\hline $\begin{array}{l}\text { +user } \\
\text { +Password }\end{array}$ & \multirow{3}{*}{$\begin{array}{l}\text { +kdIndustri } \\
\text { +NmIndustri } \\
\text { +Alamat } \\
\text { +jmIPekerja } \\
\text { +jmIModal } \\
\text { +jmlproduksi }\end{array}$} & \multirow{2}{*}{$\begin{array}{l}\text { +parameter } \\
\text { +jmlklaster } \\
\text { +Pembobot } \\
\text { +MaxItr } \\
\text { +kriteria }\end{array}$} \\
\hline \multirow{4}{*}{$\begin{array}{l}+ \text { Add() } \\
+ \text { Delete() } \\
+ \text { Edit() } \\
+\operatorname{login}() \\
+\operatorname{logout}()\end{array}$} & & \\
\hline & & \multirow{3}{*}{$\begin{array}{l}\text { +Add() } \\
\text { +Edit() } \\
\text { +Delete() } \\
\text { + Report() } \\
\text { +Count() } \\
\text { +Div() } \\
\text { +multiply() }\end{array}$} \\
\hline & $\begin{array}{l}\text { +Add() } \\
\text { +Edit() } \\
\text { +Delete() } \\
\text { +Report() }\end{array}$ & \\
\hline & & \\
\hline
\end{tabular}

Gambar 2. Struktur dan Hubungan Class Diagram 


\subsubsection{Diagram Layout}

Aplikasi ini dibangun dengan menggunakan untuk mengimplementasikan konsep klastering. Desain tampilan akan disesuaikan dengan aplikasi yang akan digunakan. Pada gambar 3 ditunjukkan salah satu tampilan utama aplikasi.

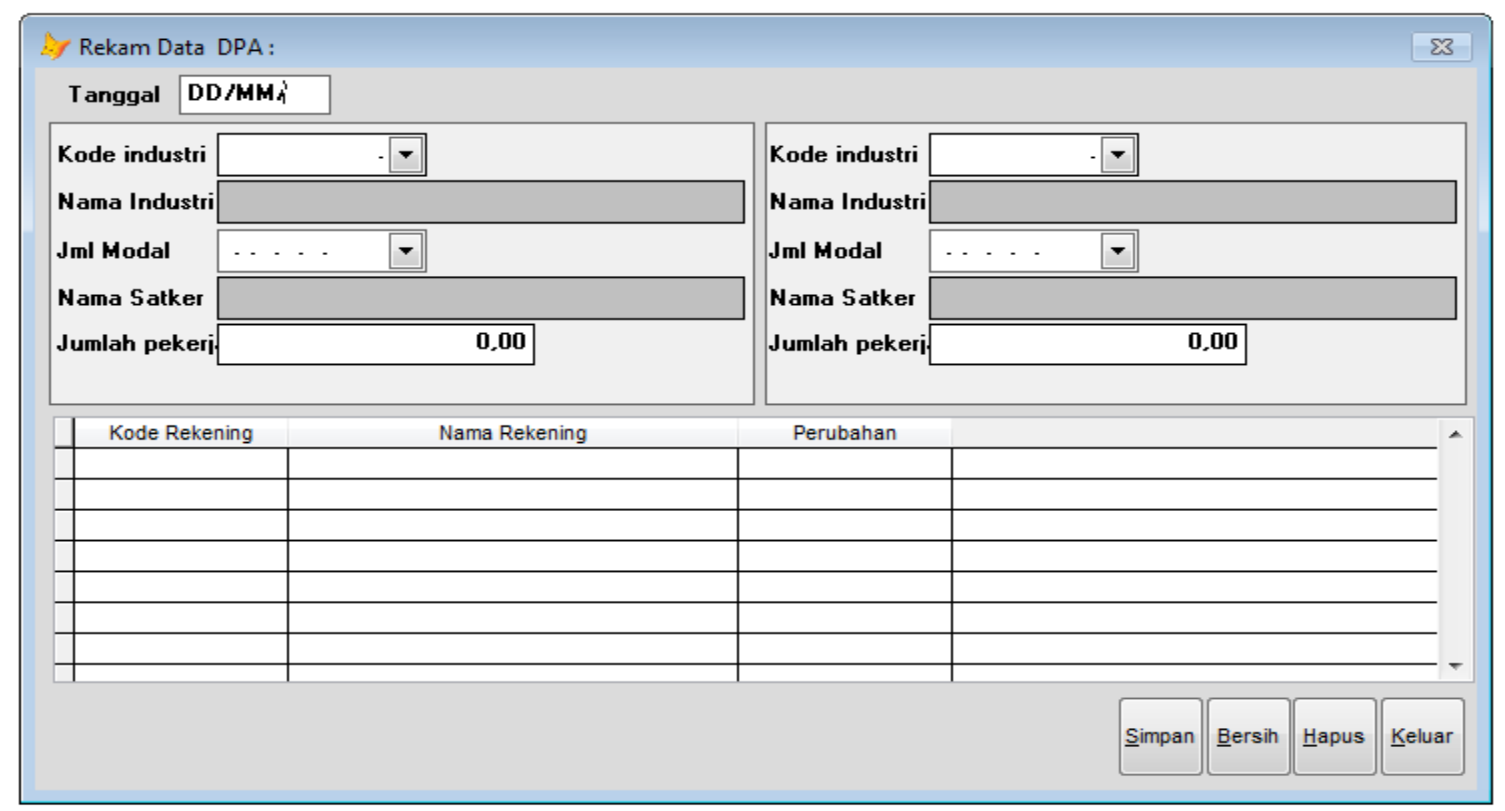

Gambar 3. Tampilan Layout Klastering

\section{KESIMPULAN}

Dari penelitian yang sudah dilakukan dapat diambil kesimpulan bahwa:

1) Analisa perancangan sistem Klastering Industri Di Kabupaten Kudus Menggunakan Metode Fuzzy C-Means melalui diagram Use Case yang dihasilkan menyediakan fasilitas untuk menggunakan aplikasi dalam pembuatan klaster industri.

2) Amalisa perancangan sistem informasi Klastering Industri Di Kabupaten Kudus Menggunakan Metode Fuzzy C-Means memberikan alternatif bagi pengguna untuk bisa menyelesaikan pekerjaannya menggunakan sistem terkomputerisasi.

3) Klastering Industri Di Kabupaten Kudus Menggunakan Metode Fuzzy C-Means ini menggunakan 3 tabel yaitu tbklastering, tbdtindustri dan tb_user.

\section{DAFTAR PUSTAKA}

[1] Al Kahfi, A.Z. (2013). Sistem Pengolahan Data Mining Indsutri Sepatu Menggunakan Metode KMeans Clustering di Jawa Tengah. Tugas Akhir, Universitas Dian Nuswantoro Semarang.

[2] Ernawati, M.U.J., Dewi, C., Mardji. 2014. "Penerapan Algoritma Fuzzy C-Means dalam Pengelompokkan Data Tingkat Banjir Limpasan”. Jurnal Mahasiswa PTIIK UB. Universitas Brawijaya.

[3] Ross. T. J. (2005). Fuzzy Logic With Engineering Applications. John Wiley \& Sons Inc, Inggris.

[4] Booch, Grady,. Maksimchuk, Robert A., Engle, Michael W., Young, Bobbi J., Conallen, Jim,. Houston, Kelli A., 2007, "Object-Oriented Analysis and Design with Applications". Pearson Education, Inc, USA. Chapter 5, 147 - 154. 
[5] Ward, John. and Joe Peppard. (2002). Strategic Planning for Information System 3nd ed. England: John Wiley \& Sons 